\title{
Characterization of Methicillin resistant Staphylococcus aureus strains from clinical isolates in a tertiary care hospital of south India
}

\author{
Geeta $\mathrm{SH}^{* 1}$, Kalghatgi $\mathrm{AT}^{2}$, Rama $^{\mathrm{NK}}{ }^{3}$ \\ Department of Microbiology, MVJ Medical College \& Research Hospital, Hoskote, Bangalore, India
}

Address for correspondence: Dr Geeta S H, Email: drgeetashashikant@gmail.com

\begin{abstract}
Methicillin resistant staphylococcus aureus (MRSA) strains which are the most frequent cause of hospital acquired infections (HAI), are also currently encountered with increasing frequency in the community. Phenotypic detection of methicillin resistance is inadequate, due to environmental factors \& heterogeneous resistant strains which may affect the phenotypic expression of resistance. Phenotypic methods for MRSA detection have been compared with the gold standard which is Polymerase Chain Reaction (PCR) for mecA gene. Discrepancies in detection have an adverse effect on patient management, thereby highlighting the importance of accuracy in diagnosis. Therefore rapid \& accurate identification is essential for both implementation of infection control measures \& prevention of nosocomial spread of the organism. Materials \& Methods: 166 S. aureus isolates were studied out of a total of 677 staphylococcal samples. Methicillin resistance were detected using oxacillin disc diffusion (ODD), cefoxitin disc diffusion (CxDD), oxacillin screen agar (OSA) \& PCR for mecA gene, using standard protocol. Results: Out of 166 S. aureus isolated, MRSA prevalence was seen in $26.5 \%$. MRSA was identified in $44(100 \%)$ by CxDD, $43(98 \%)$ by OSA and 38 (86.4\%) by ODD methods respectively. When these isolates were tested with molecular methods, the CxDD and PCR test results were comparable. However by antibiotic susceptibility test (AST), no strain was resistant to vancomycin, linezolid \& teicoplanin. Conclusion: To reduce the prevalence of MRSA, regular surveillance of HAI \& monitoring of AST is the need of the hour. Proper detection of all MRSA isolates with rapid \& accurate methods must be done as a routine laboratory procedure.
\end{abstract}

Keywords: $S$. aureus, MRSA, phenotypic tests, AST, mecA gene.

\section{Introduction}

Staphylococcus aureus (S. aureus) is a bacteria of significant importance because of its ability to cause a wide range of diseases and its capacity to adapt to diverse environmental forms. $S$. aureus is a gram positive organism that serves as an opportunistic pathogen \& frequent colonizer of epithelium causing severe diseases in man \& animals $[1,2]$.

The incidence of Methicillin Resistant Staphylococcus aureus (MRSA) in India ranges from $30-70 \%$. MRSA strains harbour mecA gene which encodes a modified (Penicillin binding protein) PBP2a with low affinity for methicillin and all $\beta$-lactam antibiotics. Since MRSA are resistant to all $\beta$-lactam antibiotics, the therapeutic options are limited significantly, and therefore their

Manuscript Received: $24^{\text {th }}$ Sept 2015

Reviewed: $7^{\text {th }}$ Oct 2015

Author Corrected: $17^{\text {th }}$ Oct 2015

Accepted for Publication: $27^{\text {th }}$ Oct 2015 accurate identification becomes important. Phenotypic expression of methicillin resistance may alter depending on the growth conditions of $S$. aureus which may affect the accuracy of the methods used to detect methicillin resistance [3].

There are many methods available for the detection of MRSA. Cefoxitin is a potent inducer of mecA gene regulatory system. In recent years there are multiple published-reports which suggest the use of cefoxitin as surrogate marker for the detection of mecA gene mediated $S$. aureus resistance. Clinical Laboratory Standards Institute (CLSI) guidelines recommend cefoxitin to be used to identify MRSA, using a $30 \mu \mathrm{g}$ cefoxitin disc and a zone of $\leq 19 \mathrm{~mm}$ is considered as resistance strain [4].

The introduction of methicillin in 1960s had an important impact on the treatment of infections caused 
by penicillinase producing $S$. aureus. Shortly later, MRSA strains with a PBP appeared and spread worldwide. Such resistance mechanism is due to production of a modified PBP2a with low affinity to $\beta$ lactam antibiotics as a result of the acquisition of a $m e c A$ gene. It can be difficult to detect MRSA because of the heterogeneous nature of methicillin resistance. The mecA gene is highly conserved among the Staphylococcal species and consequently, the detection of this gene by the PCR is considered as the "gold standard" for the detection of methicillin resistance in Staphylococci. The existence of the mecA gene in $S$. aureus characterizes methicillin resistance [5].

Staphylococcal resistance was reported shortly after penicillin was introduced, and within approximately 5-6 years, $25 \%$ of community isolates were penicillin resistant. Although the rates are only approximate because they are based on reports from numerous locations, a clear correlation exists between the prevalence of penicillin resistant strains of $S$. aureus reported in hospitals and rates in the community. Strains of MRSA, which had been largely confined to hospitals and long-term care facilities, are emerging in the community. The changing epidemiology of MRSA bears striking similarity to the emergence of penicillinase mediated resistance in $S$. aureus since decades ago. Even though the origin (hospital or the community) of the emerging MRSA strains is not known, the prevalence of these strains in the community seems likely to increase substantially [6].

Resistance to penicillin is determined by the mecA gene, which encodes the low affinity PBP2a. Lately, new methicillin resistance gene, mec $C$ has been discovered from humans, animals and food products. This new mecA homolog has been detected in bacteria from dairy cattle in England and humans in England, Scotland and Denmark. This newly identified protein has $\mathrm{a} \leq 63 \%$ similarity with the PBP 2 a encoded by $\operatorname{mec} A$ [7].

Laboratory diagnosis and susceptibility testing are crucial steps in the treatment, control and prevention of MRSA infections. Hence methods used to detect MRSA in clinical samples should have high sensitivity and specificity with the results available within a short time. Various methods have evolved for rapid detection of MRSA but the optimal method remains controversial. The most commonly used methods in laboratories are culture and sensitivity test, oxacillin disc diffusion (ODD), mannitol salt agar (MSA), oxacillin screen agar
(OSA), broth and agar dilution tests etc. All these are conventional phenotypic methods of MRSA

identification. Genotypic method is the polymerase chain reaction (PCR) based method for detecting mecA gene which remains the gold standard for MRSA [8].

The phenotypic methods in general are easier to perform and interpret, cost effective and are widely available, however less discriminatory. The genotypic methods are expensive and technically demanding, and more precise. Newer technologies involving sequencing of various genes are coming up as broadly applicable typing systems. Still there is no consensus regarding the single best method for detection of MRSA strains. Application of any identification method requires careful assessment of its suitability and an individual approach depending on the purpose of the study [9].

\section{Aims and Objectives}

1. To study the prevalence of MRSA in a tertiary care hospital.

2. To compare the various phenotypic methods for isolation of MRSA.

3. Detection of mecA gene by genotyping for confirmation of the isolated MRSA strains.

\section{Materials \& Methods}

The study was conducted in our teaching hospital from Jan - Dec 2014. The study was commenced after getting the ethical clearance from the Institutional Ethics Committee.

From a total of 677 staphylococci studied from various clinical samples, 166 S. aureus strains were isolated, identified and characterized as per recommended standard protocol $[10,11]$.

All the isolates were tested for methicillin resistance by disc diffusion using oxacillin $(1 \mu \mathrm{g})$, cefoxitin $(30 \mu \mathrm{g})$, MSA \& OSA methods [Himedia India].

The isolates were subjected to AST by Kirby Bauer disc diffusion method.

Antibiotics tested were penicillin (10 units), ampicillin $(10 \mu \mathrm{g})$, cephalexin $(30 \mu \mathrm{g})$, oxacillin $(1 \mu \mathrm{g})$, cefoxitin $(30 \mu \mathrm{g})$, erythromycin $(15 \mu \mathrm{g})$, clindamycin $(2 \mu \mathrm{g})$, ciprofloxacin $(5 \mu \mathrm{g})$, ofloxacin $(10 \mu \mathrm{g})$, gentamycin $(10 \mu \mathrm{g})$, amikacin $(30 \mu \mathrm{g})$, linezolid $(30 \mu \mathrm{g})$, vancomycin $(30 \mu \mathrm{g})$, cotrimoxazole $(25 \mathrm{mcg}) \&$ teicoplanin $(30 \mu \mathrm{g})$. 
Zone diameters were measured as per CLSI criteria [11].

Oxacillin screen agar: Mueller Hinton agar (MHA) with $4 \% \mathrm{NaCl}$ and oxacillin $6 \mu \mathrm{g} / \mathrm{ml}$ was prepared. The 0.5 McFarland suspension of the test strains was inoculated as spots over the plates, incubated at $35^{\circ} \mathrm{C}$ for 24 hours. The strains which were able to grow on this medium were designated as MRSA.

Oxacillin and cefoxitin disc diffusion test: MHA plates were overlaid with a saline suspension of the isolate (0.5 McFarland), cefoxitin $(30 \mu \mathrm{g})$ and oxacillin $(1 \mu \mathrm{g})$ were placed on the plates. After 24-48 hours of incubation at $35^{\circ} \mathrm{C}$, the plates were read using CLSI cut off points as reistant $(<19 \mathrm{~mm}$ cefoxitin; <10mm oxacillin).

Molecular detection of mecA gene by PCR: S. aureus DNA extraction was performed by using Gene Elute Genomic DNA kit (Sigma Aldrich). The primers used for detection of mecA gene were [12]:

mecA1: 5' - GTAGAAATGACTGAACGTCCGATAA mecA2: 5' - CCAATTCCACATTGTTTCGGTCTAA
The target gene was amplified using the above set of primers by PCR in a $100 \mu$ l of reaction mixture containing dNTPs $(200 \mu \mathrm{M}), 2.5 \mu \mathrm{M}$ (each primers), $2.5 \mathrm{U}$ of Taq DNA polymerase (Bangalore Genei), $50 \mathrm{mM} \mathrm{KCl}, 10 \mathrm{mM}$ Tris- $\mathrm{HCl}, 1.5 \mathrm{mM} \mathrm{MgCl} 2 \& 0.01 \%$ gelatin.

The procedure steps were as follows: Pre-denaturation for 4 minutes at $94^{\circ} \mathrm{C}$, denaturation for $45 \mathrm{~s}$ at $94^{\circ} \mathrm{C}$ : annealing for $45 \mathrm{~s}$ at $55^{\circ} \mathrm{C}$, primer extension for $1 \mathrm{~min}$ at $72^{\circ} \mathrm{C}$. Each step was repeated 30 times. For visualization, $10 \mu \mathrm{l}$ of PCR amplicon was loaded in $2 \%$ agarose gel with ethidium bromide. The band of amplified DNA was visualised under UV transilluminator. A $310 \mathrm{bp}$ amplicon corresponds to the $m e c A$ gene shown in the fig [13].

\section{Quality Control}

1. S. aureus ATCC 25923 was used as standard control strain.

2. In-house strain of $S$. aureus showing sensitivity to cefoxitin.

The viability of the isolates, was maintained by periodic subculture on semi-solid nutrient agar.

\section{Results}

Out of the 677 Staphylococcal isolates from various clinical specimen, S. aureus was present in 166 samples (24.5\%).

Out of 166 S. aureus, MRSA was the isolate in $44(26.5 \%)$.

Table 1 shows the Sample-wise distribution of MRSA: Pus 29 (65.9\%), Blood 13 (29.5\%) and ET tip 02 (4.6\%). The maximum isolation of MRSA was from surgical departments (45.4\%) - Surgery 14 (31.8\%) \& Orthopaedics 06 (13.6\%).

Table 1. Sample-wise distribution of MRSA isolates:

\begin{tabular}{|l|c|c|c|c|c|c|c|c|c|}
\hline & MED & SUR & PAED & ORTHO & OBG & DERMO & ENT & ICU & Total (44) \\
\hline BLOOD & 01 & - & 12 & - & - & - & - & - & $13(29.5 \%)$ \\
\hline PUS & - & 14 & 02 & 06 & 04 & 01 & 01 & 01 & $29(66.0 \%)$ \\
\hline ET Tip & 01 & - & - & - & - & - & - & 01 & $02(4.5 \%)$ \\
\hline \% & 4.5 & 31.8 & 31.8 & 13.6 & 09 & 2.4 & 2.4 & 4.5 & \\
\hline
\end{tabular}

Table 2 shows the phenotypic \& genotypic characteristics of MRSA isolates: MRSA detection by OSA \& CxDD was $98 \%$ \& $100 \%$ and by ODD method it was $86.4 \%$; mecA gene detection by molecular methods gave comparable results with that of CxDD.

Table 2. Phenotypic and Genotypic characteristics of MRSA strains:

\begin{tabular}{|l|c|c|}
\hline & MRSA (44) & \% \\
\hline Oxacillin Disc Diffusion & 38 & 86.4 \\
\hline Cefoxitin Disc Diffusion & 44 & 100 \\
\hline Oxacillin Screen Agar & 43 & 98 \\
\hline mecA gene by PCR & 44 & 100 \\
\hline
\end{tabular}


Table 3 shows the antibiotic susceptibility pattern of the MRSA strains: The isolates were highly resistant to cefoxitin (100\%), ampicillin (95.5\%), cephalexin $(95.5 \%)$, ciprofloxacin \& gentamycin $(75 \%)$ each \& erythromycin $(68 \%)$; and were moderately resistant to cotrimoxazole $(48 \%) \&$ clindamycin $(52 \%)$. All the strains were $100 \%$ sensitive to linezolid, teicoplanin \& vancomycin.

\section{Table 3. Antibiotic Susceptibility Pattern of MRSA strains:}

\begin{tabular}{|l|l|l|l|l|l|l|l|l|l|l|l|l|}
\hline & Amp & E & Co & Cd & Lz & Tei & Va & Cx & Cp & Cf & Of & G \\
\hline Sensitive & 02 & 14 & 23 & 21 & 44 & 43 & 44 & - & 02 & 11 & 14 & 11 \\
\hline$\%$ & 4.5 & 32 & 52 & 48 & 100 & 98 & 100 & - & 4.5 & 25 & 32 & 25 \\
\hline Resistant & 42 & 30 & 21 & 23 & - & 01 & - & 44 & 42 & 33 & 30 & 33 \\
\hline$\%$ & 95.5 & 68 & 48 & 52 & - & 02 & - & 100 & 95.5 & 75 & 68 & 75 \\
\hline
\end{tabular}

Antibiotics: Ampicillin, Erythromycin, Cotrimoxazole, Clindamycin, Linezolid, Teicoplanin, Vancomycin, Cefoxitin, Cephalexin, Ciprofloxacin, Ofloxacin, Gentamicin

Table 4. Statistical analysis of data in different studies:

\begin{tabular}{|l|c|c|c|c|c|}
\hline & $\begin{array}{c}\text { MFSA } \\
(\%)\end{array}$ & $\begin{array}{c}\text { ODD } \\
(\%)\end{array}$ & $\begin{array}{c}\text { CxDD } \\
(\%)\end{array}$ & $\begin{array}{c}\text { OSA } \\
(\%)\end{array}$ & $\begin{array}{c}\text { mecA } \\
(\%)\end{array}$ \\
\hline Present Study 2015 & $\mathbf{2 6 . 5}$ & $\mathbf{8 6 . 4}$ & $\mathbf{1 0 0}$ & $\mathbf{9 8}$ & $\mathbf{1 0 0}$ \\
\hline Manju Pillai 2014 & 37.5 & 93 & 98 & 98 & $\mathbf{1 0 0}$ \\
\hline James John 2012 & 60 & 65 & 76 & 68 & 76 \\
\hline Pramodhini 2011 & 36.4 & 90 & 100 & 100 & 100 \\
\hline Kumar S 2009 & 56 & 85 & 100 & 96 & 98 \\
\hline Murakami K 1991 & 53 & 98 & 98 & 98 & 100 \\
\hline
\end{tabular}

Oxacillin disc diffusion (ODD), Cefoxitin disc diffusion (CxDD), Oxacillin screen agar (OSA).

Figure I: Shows the different tests used in characterization of Methicillin resistant Staphylococcus aureus

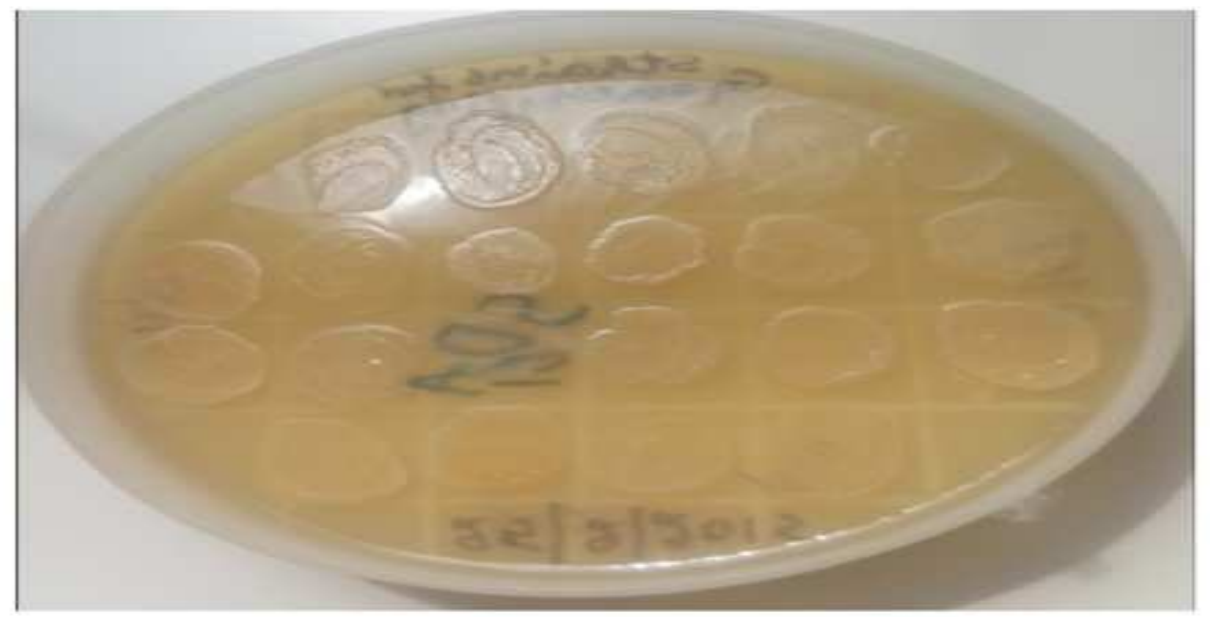

Methicillin Resistant Staphylococcus aureus on Oxacillin Screen Agar

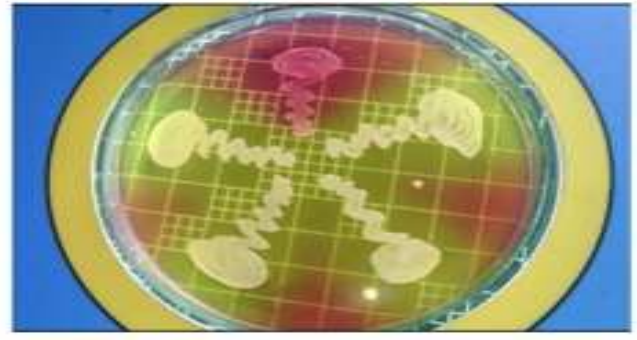

Mannitol Salt Agar with $S$. aureus

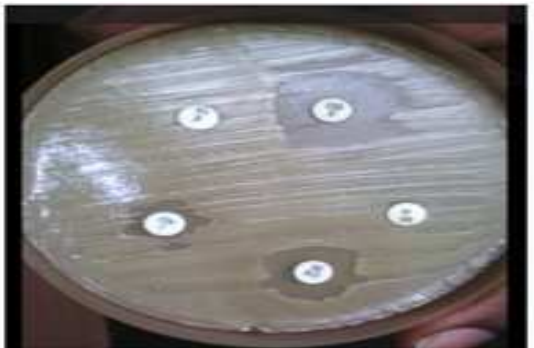

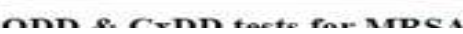


Figure II: Shows the Genotyping results of the MRSA Isolates in the study

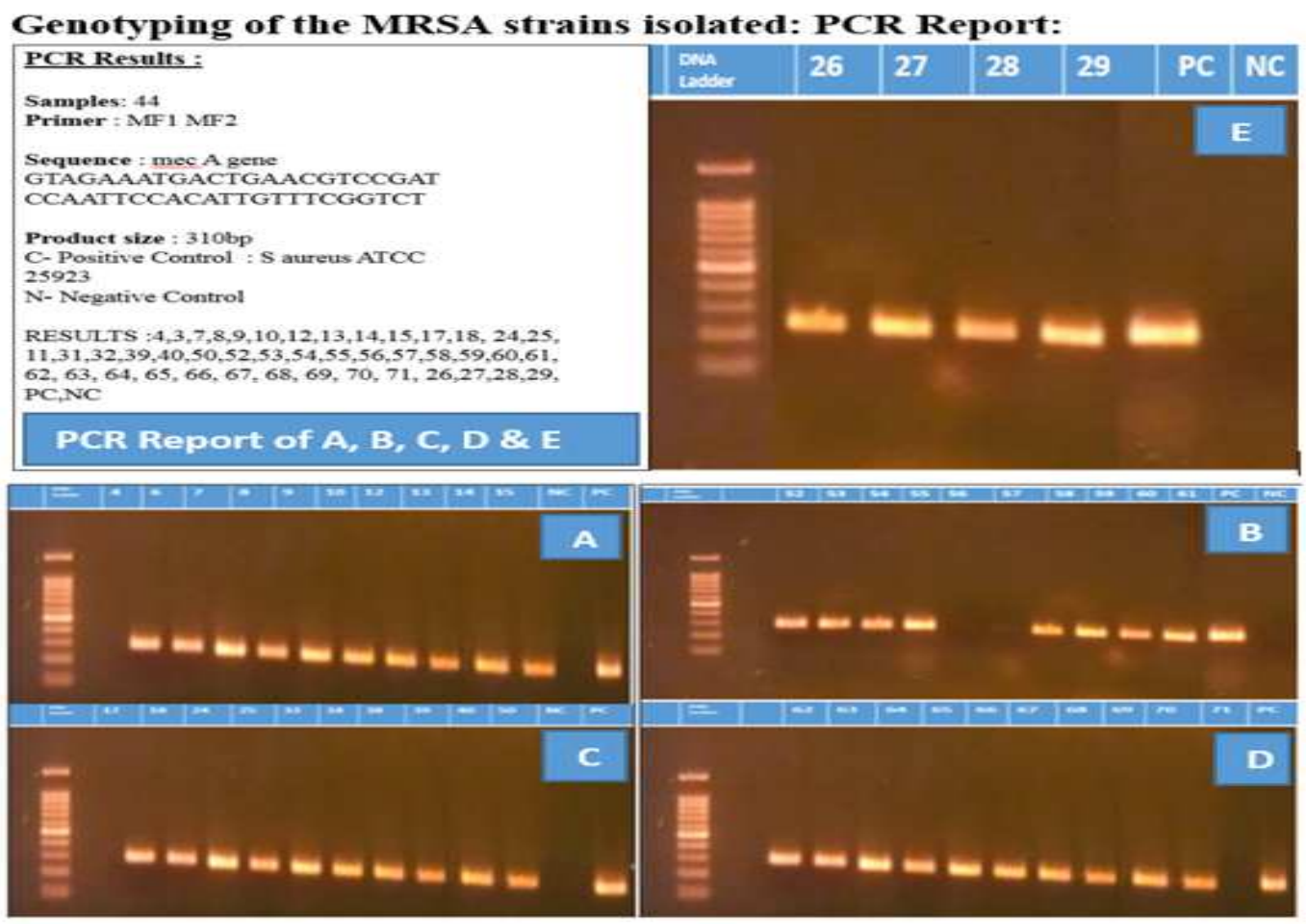

\section{Discussion}

MRSA are being recognised as important human pathogens causing significant morbidity \& mortality in hospitals and community; and are difficult to eradicate because they are multi-drug resistant. With reference to world-wide resistance among $S$. aureus strains, early detection of reduced susceptibility to $\beta$-lactam antibiotics is important for clinicians. CLSI recommends use of cefoxitin as preferred method for testing $S$. aureus as surrogate marker for detecting oxacillin resistance. Detection of mecA gene or its product $\mathrm{PBP} 2 \mathrm{a}$ is considered the gold standard for MRSA confirmation [11]. The prevalence of MRSA in our hospital was found to be $26.5 \%$. Similar isolation rates were also found in studies byKumari $\mathrm{N}$ et al \&Pramodhini Set al [14, 15].Higher prevalence rates ranging from $40-60 \%$ were found in some studies [16, 17]. This variation might be because of changes in antibiotic usage \& infection control practices in different hospitals.

In the present study, maximum isolation of MRSA was from Surgery \& Paediatrics departments (31.8\%) each, followed by Ortho (13.6\%), OBG (9\%) \& Medicine $(4.5 \%)$ which correlates with pus, blood \& other samples. Similar results were reported by Kumari $\mathrm{N}$ et al \&Pramodhini $\mathrm{S}$ et al., which can be explained by the

fact that Staphylococcus will be present as part of the commensal flora of the skin $[14,15]$.

CxDD was found to be highly sensitive \& specific $(100 \%)$ while sensitivity \& specificity of ODD was $94 \% \& 80 \%$. The results of disc diffusion methods showed that $\mathrm{CXDD}$ is a better alternative for MRSA detection. Similar results were quoted in several other studies $[3,8,18,15,21]$.

Sensitivity \& specificity of OSA were $100 \%$ \& $99 \%$. Similar finding were reported by Pramodhini $\mathrm{S}$ et al, Kumar S et al, Murakami K et al \& Manju Pillai et al $[15,18,21,8]$.

In the present study, isolated MRSA strains were $100 \%$ sensitive to linezolid, vancomycin \& teicoplanin. The isolates were highly resistant to cefoxitin, ampicillin \& cephalexin $(95-100 \%)$. The isolates showed varying resistance to other antibiotics like erythromycin $(68.2 \%)$, clindamycin $(52 \%) \&$ cotrimoxazole $(48 \%)$. 
AST report in the present study was coherent with that in the study by Anupurba et al [17].

Our study showed sensitivity \& specificity of genotyping by PCR for MRSA to be $100 \%$ which was in concordance with other studies like James John et al, Kumar S et al, Manju Pillai et al, Swenson JM et al \& Fernandes CJ et al [4, 18, 8, 19, 20].

\section{Conclusion}

Rapid and accurate identification of MRSA is required for therapeutic and epidemiological reasons; to immediately start appropriate antimicrobial therapy \& to avoid the spread of these strains. Phenotypic methods are still preferred for species identification. But for the reliable detection of MRSA an algorithm should include a combination of tests; and apply a genotypic method for confirmation of resistant isolates showing discordant results. The hospital infection control policy \& guidelines should be strictly implemented so as to enable clinicians to deliver better and proper health care to the patients. Results of cefoxitin disc diffusion test is in concordance with the genotyping results for mecA gene. So this test can be an alternative to PCR for detection of MRSA in resource constraint settings.

Conflict of interest: None declared.

Funding: Nil, Permission from IRB: Yes

\section{References}

1. Lowy FD. Staphylococcus aureus infections. N Engl J Med. 1998 Aug 20;339(8):520-32.

2. Hafsat Ali Grema, Yaqub Ahmed Geidam, Galadima Bala Gadzama, James Agbo Ameh, Abubakar Suleiman. Methicillin Resistant Staphylococcus aureus: A Review. Adv Anim Vet Scien. 2015; Vol 3 (2): 79 98.DOI

http://dx.doi.org/10.14737/journal.aavs/2015/3.2.79.98

3. Mathews AA, Thomas M, Appalaraju B, Jayalakshmi J. Evaluation and comparison of tests to detect methicillin resistant $S$. aureus. Indian $J$ Pathol Microbiol. $2010 \quad$ Jan-Mar;53(1):79-82. doi: 10.4103/0377-4929.59189.

4. Sangeetha G, James John, Ranjith J. Comparison of different phenotypic methods with PCR detection of mecA gene for detection of Methicillin Resistant Staphylococcus aureus. Int J Pharmacy and
Pharmaceutica Sci. 2012; Vol 4 (Suppl 4): 495-7. ISSN0975-1491.

5. Mounir M Salem Behkit. Phenotypic and Genotypic characterisation of Staphylococcus aureus isolates with reference to Methicillin resistance. Trop J Pharma Res. 2014; $13 \quad$ (8): 1239-1246.DOI । http://dx.doi.org/10.4314/tjpr.v13i8.7ISSN: 1596-5996 (print); 1596-9827 (electronic)

6. Chambers HF. The changing epidemiology of Staphylococcus aureus? Emerg Infect Dis. 2001 MarApr;7(2):178-82.

7. Porrero MC, Valverde A, Fernández-Llario P, DíezGuerrier A, Mateos A, Lavín S, Cantón R, FernándezGarayzabal JF, Domínguez L. Staphylococcus aureus carrying mecC gene in animals and urban wastewater, Spain.Emerg Infect Dis. 2014 May;20(5):899-901. doi: 10.3201/eid2005.130426.

8. Pillai MM, Latha R, Sarkar G. Detection of methicillin resistance in Staphylococcus aureus by polymerase chain reaction and conventional methods: a comparative study. J Lab Physicians. 2012 Jul;4(2):838. doi: 10.4103/0974-2727.105587.

9. Mehndiratta PL, Bhalla P. Typing of Methicillin resistant Staphylococcus aureus: a technical review. Indian J Med Microbiol. 2012 Jan-Mar;30(1):16-23. doi: 10.4103/0255-0857.93015.

10. Collee JG, Fraser AG, Duguid JP, Marmion BP, Simmons A. Mackie \& McCartney Practical Medical Microbiology. 1996. 14 ${ }^{\text {th }}$ Ed. Churchill Livingstone, New York.

11. Clinical \& Laboratory Standard Institute. Performance standards for antimicrobial susceptibility testing; twenty third informational supplement. CLSI document. Wayne, PA. 2013; CLSI: M100 - S23.

12. Geha DJ, Uhl JR, Gustaferro CA, Persing DH. Multiplex PCR for identification of methicillin-resistant staphylococci in the clinical laboratory. J Clin Microbiol. 1994 Jul;32(7):1768-72.

13. Protocol for PCR amplification of mecA, mecC, SPA \& PVL (recommended by EURL-AR). DTU National Food Institute, Sep 2012. $2^{\text {nd }}$ version, $1-5$. 
14. Kumari N, Mohapatra TM, Singh YI. Prevalence of Methicillin-resistant Staphylococcus aureus (MRSA) in a Tertiary-Care Hospital in Eastern Nepal. JNMA J Nepal Med Assoc. 2008 Apr-Jun;47(170):53-6.

15. Pramodhini S, Tenmozhivalli PR, Selvi R, Dillirani $\mathrm{V}$, Vasumathi A, Agatha D. Comparision of various phenotypic methods \&mecA based PCR for the detection of MRSA. J Clin Diagn Res. 2011;5(7):1359 -62 .

16. Muralidharan S. Special article on Methicillin Resistant S. aureus. J Acad Clin Microbiol. 2009; 11: $15-16$.

17. Anupurba S, Sen MR, Nath G, Sharma BM, Gulati AK, Mohapatra TM. Prevalence of methicillin resistant Staphylococcus aureus in a tertiary referral hospital in eastern Uttar Pradesh. Indian J Med Microbiol. 2003 Jan-Mar;21(1):49-51.
18. Anand KB, Agrawal P, Kumar S, Kapila K. Comparison of cefoxitin disc diffusion test, oxacillin screen agar, and PCR for mecA gene for detection of MRSA. Indian J Med Microbiol. 2009 JanMar;27(1):27-9.

19. Swenson JM, Tenover FC; Cefoxitin Disk Study Group. Results of disk diffusion testing with cefoxitin correlate with presence of mecA in Staphylococcus spp. J Clin Microbiol. 2005 Aug;43(8):3818-23.

20. Fernandes CJ, Fernandes LA, Collignon P; Australian Group on Antimicrobial Resistance. Cefoxitin resistance as a surrogate marker for the detection of methicillin-resistant Staphylococcus aureus. J Antimicrob Chemother. 2005 Apr;55(4):50610. Epub 2005 Mar 2.

21. Kazuhisa Murakami, Wakio Minamide, Koji Wada, Etuo Nakamura, Hiroshi Teraoka and Sachihiko Watanabe. Identification of Methicillin-Resistant Strains of Staphylococci by Polymerase Chain Reaction. J Clin Microbiol. 1991; Vol. 29(10): 2240 - 44.

\section{How to cite this article?}

Geeta SH, Kalghatgi AT, Rama NK. Characterization of Methicillin resistant Staphylococcus aureus strains from clinical isolates in a tertiary care hospital of south India. Int $J$ Med Res Rev 2015;3(9):1077-1083. doi: 10.17511/ijmrr.2015.i9.196. 